\title{
JUDICIALIZAÇÃO DA SAÚDE E O IMPACTO DAS DECISÕES JUDICIAIS NA GESTÃO PUBLICA
}

\section{Maria Aparecida Alves ${ }^{1}$}

Resumo: A definição da saúde como direito fundamental social, levou ao acionamento do Poder Judiciário, buscando o fornecimento de medicamentos, insumos ou serviços médico hospitalares pelo Poder Executivo, conhecido como judicialização da saúde. Este artigo discute a questão, direcionado para o impacto na gestão publica e como esta tem recepcionado tais comandos judiciais, cuja trajetória se mostra constante. Trata-se de uma análise teóricobibliográfica de cunho dedutivo que busca examinar se estas decisões ensejam o processamento de mudanças em sua estrutura organizacional.

Palavras-chave: judicialização da saúde - interesse particular - interesse coletivo - impacto - gestão pública

\section{JUDICIALIZATION OF HEALTH AND THE IMPACT OF JUDICIAL DECISIONS ON PUBLIC MANAGEMENT}

Abstract: The definition of health as a fundamental social right, led to the activation of the Judiciary, seeking the supply of medicines, supplies or hospital medical services by the Executive Branch, known as health judicialization. This article discusses the issue, directed at the impact on public management and how it has received such judicial commands, whose trajectory is constant. It is a theoretical-bibliographic analysis of a deductive nature that seeks to examine if these decisions allow the processing of changes in their organizational structure.

Keywords: health judicialization - private interest - collective interest - impact - public administration

\section{INTRODUÇÃO}

O direito à saúde não abrange apenas a assistência médico-hospitalar, limitando-se a oferta de procedimentos e medicamentos disponíveis. Tampouco a saúde é sinônimo de ausência de enfermidade. Consiste em estado de bem-estar físico, mental e social, segundo a Organização Mundial da Saúde. E, ao Estado, cabe não somente promover medidas como ofertas de procedimentos e medicamentos, mas também, promover medidas preventivas como políticas de saneamento básico, vigilância sanitária, entre outras, no objetivo de cumprir o mandamento constitucional em apreço.

\footnotetext{
${ }^{1}$ Mestranda em Direito - Proteção dos direitos fundamentais pela Universidade de Itaúna. Bacharel em Direito pela Faculdade de Direito do Oeste de Minas. Advogada.
}

Revista Brasileira de Direitos e Garantias Fundamentais | e-ISSN: 2526-0111 | Porto Alegre | v. 4 | n. 2 |

p. 99 - 113 | Jul/Dez. 2018 
Apesar de ser dever do Estado a garantia do acesso a serviços e ações de saúde, a demanda se manifesta muito superior a capacidade do Estado, o que acaba gerando insatisfações individuais, que chegam ao Poder Judiciário, que é chamado a intervir nestes impasses, para obrigar o ente público a prestar o atendimento nos moldes dos pleitos formulados.

O Judiciário, muitas vezes, diante de demandas que pleiteiam a concessão de medicamentos de alto custo, cirurgias e procedimentos não disponibilizados de acordo com a necessidade particular de quem a busca e, sobretudo, se atendo ao disposto na Carta Magna de 1988, determina o provimento do mérito, desconsiderando, em sua maioria, a falta de recursos humanos, materiais e/ou financeiros da estrutura organizacional do Estado, o que acarretará, por conseguinte, uma série de restrições na implantação de políticas públicas, a partir de tais decisões.

Esta intervenção do judiciário acaba gerando um conflito de poderes, entre o Executivo e o Judiciário, considerando a autonomia de cada um. Várias são as decisões que acabam resultando em impacto econômico para a administração pública com o desvio de finalidade de certos recursos para o estrito cumprimento de decisões judiciais que obrigam o Estado a cumprir uma demanda de interesse particular. Por vezes, tais decisões acabam por sacrificar projetos que beneficiariam a coletividade.

Desse modo, o presente estudo analisa o impacto das decisões judiciais na concessão de medidas que determinam a atuação do Estado perante um interesse individual, sendo um estudo de natureza teórico-bibliográfica, de cunho dedutivo, já que parte da análise do direito fundamental à saúde para concentrar a pesquisa na intervenção do poder judiciário na efetivação desse direito à saúde. Com vistas a atingir o objetivo proposto, inicia-se a abordagem com apontamentos relevantes acerca do direito à saúde e, na sequência, traz a responsabilidade do Estado em garantir o acesso eficaz a esse direito, trabalhando a noção de judicialização na esfera da saúde, para, finalmente, demonstrar quais são os impactos das decisões judicias na esfera pública.

\section{A SAÚDE COMO DIREITO E DEVER FUNDAMENTAL}


O direito à saúde, em virtude do seu atributo de direito fundamental, recebeu a qualificação de norma constitucional de eficácia plena, ou seja, possui força normativa suficiente para sua incidência imediata e independente de providência normativa ulterior para sua aplicação. O caráter pleno de eficácia de uma norma diz respeito à ideia de que, desde a entrada em vigor da Constituição, tais normas produzem, ou têm a possibilidade de produzir, todos os efeitos essenciais relativos aos interesses, comportamentos e situações, que o constituinte direta e normativamente quis regular, sendo garantida a existência de um aparato jurídico- institucional para a sua efetivação. Neste contexto, atribuiu-se às ações e serviços de saúde o caráter de relevância pública (SARLET, 2001).

Flávia Piovesan pondera que:

\begin{abstract}
Ao analisarmos a carta dos direitos fundamentais expostos pela Constituição, percebemos uma sintonia com a Declaração Universal de 1948, bem como com os principais pactos sobre os Direitos Humanos, dos quais o Brasil é signatário. Intensifica-se a interação e conjugação do Direito internacional e do Direito interno, que fortalecem a sistemática de proteção dos direitos fundamentais, com uma principiologia e lógica, fundadas na primazia dos direitos humanos. (PIOVESAN, 1996, p. 47)
\end{abstract}

Conforme José Afonso da Silva:

É a primeira vez que uma Constituição assinala, especificamente, objetivos do Estado brasileiro, não todos, que seria despropositado, mas os fundamentais, e entre eles, uns que valem como base das prestações positivas que venham a concretizar a democracia econômica, social, e cultural a fim de efetivar a dignidade da pessoa humana.(SILVA, 1997, p. 93)

Deste modo, verifica-se que a Constituição Federal de 1988 previu especificamente, de forma inovadora, os direitos fundamentais garantidos à população, ou seja, direitos que não podem ser abdicados e que devem ser garantidos obrigatoriamente pelo Estado.

Esse preceito de direito fundamental depende de amplo e rígido processo legislativo, o que cristaliza justamente sua relevância jurídica, política e social no ordenamento brasileiro. O direito à saúde ainda se constitui como clausula pétrea no âmbito constitucional, uma vez que, em virtude de sua associação direta com o direito à vida, não pode ser excluído do resguardo que lhe foi alçado pela Carta Constitucional.

O título II da Constituição da República Federativa do Brasil (CRFB) é uma das principais partes da Constituição, pois consagra a tábua de direitos e deveres 
fundamentais que a comunidade política brasileira reconhece, dentro outros direitos humanos, e assume o compromisso de, conjuntamente com cada um de seus integrantes, possibilitar ao máximo a vivência efetiva e equitativa, bem como a garantia do exercício harmônico de cada um destes direitos e deveres. (SEVERO, 2007, p. 69)

Com efeito, tornar a saúde um direito fundamental traz avanços e, paralelamente, novos desafios para sua implementação e efetivação. Mais precisamente, na medida em que a saúde é um direito de todos, ou seja, de mais de 180 milhões de brasileiros, surgem questões sobre como tornar este direito alcançável e exercido por todos de forma igualitária; ou, mais propriamente, como constituir um arranjo de recursos e investimentos que torne as ações em saúde uma prerrogativa efetiva de todos. Isso se torna mais complexo, ao passo que, no Brasil a efetivação da saúde é de competência concorrencial, ou seja, se constitui simultaneamente como um dever para os Municípios, os Estados e a União².

O direito à saúde, enquanto direito fundamental, se insere na categoria dos chamados direitos de titularidade coletiva. Em virtude da natureza desses direitos, no Brasil consolidouse o que comumente se denomina de litigância de interesse público, que comporta a ideia de que os direitos não se restringem às meras partes individuais, na medida em que são de titularidade de grupos e coletividades.

Em linhas gerais, Ingo Wolfgang Sarlet sustenta que tais direitos trazem como nota distintiva o fato de se desprenderem, em princípio, da figura do homem-indivíduo, como seu titular, destinando-se à proteção de grupos humanos, família, povo, nação. (SARLET, 2001, p. 52). O mesmo autor ainda sustenta que, são novas facetas do princípio da dignidade da pessoa humana, que traduz a ideia de que o Estado existe em função da pessoa humana, $e$ não o contrário, já que o homem constitui a personalidade precípua, e não meio da atividade estatal (idem, p. 103).

\footnotetext{
${ }^{2}$ Para lidar com esses novos avanços, foi promulgada a Lei $n^{\circ} 8.080 / 90$, que institui as regras e princípios que regem o Sistema Único de Saúde (SUS). O SUS configura a política de saúde brasileira como um direito de todos de forma indistinta, que possui não somente regras formais de organização, mas também, princípios jurídicos que orientam seu desenvolvimento, tais como integralidade, descentralização, participação, universalidade, etc. Admitiu-se que os princípios serviriam como guias para as ações em saúde, de modo a orientarem elementos para a constituição de uma ação integral e, ao mesmo tempo, efetiva. No mesmo ano, foi promulgada a Lei no 8.142/90, que consolidou espaços públicos de participação da sociedade civil na saúde com a regulamentação dos Conselhos de Saúde e Conferências de Saúde. Tais espaços se apresentam como relevantes para a continuidade do processo de garantia e efetivação do direito à saúde.
} 
Como direito fundamental, o direito à saúde pode ser caracterizado como típico direito-dever fundamental ${ }^{3}$, pois institui a Constituição que a saúde é um direito de todos e um dever do Estado assegurado acesso universal e igualitário às ações e serviços para promoção, proteção e recuperação. Assim, com a ideia de direito coletivo, nasce para o Estado a obrigação de garantir a efetividade do direito à saúde, como disposto na Carta Magna de 1988.

\section{A RESPONSABILIDADE DO ESTADO EM GARANTIR O DIREITO FUNDAMENTAL A SAÚDE NA CONSTITUIÇÃO FEDERAL DE 1988}

A saúde é um direito de todos e um dever do Estado - com essas palavras a Constituição Federal de 1988 abre seu artigo 196 para expressar o compromisso do Estado de garantir a todos os cidadãos o pleno direito à saúde. Essa garantia, conforme a literalidade do artigo mencionado será efetivada "mediante políticas sociais e econômicas que visem à redução do risco de doença e de outros agravos e ao acesso universal e igualitário às ações e serviços para sua promoção, proteção e recuperação".

Sobre a Constituição Federal de 1988, Bahia e Abujamra explicitam que:

(...) afinada com a evolução constitucional contemporânea e o direito internacional, incorporou o direito à saúde como bem jurídico digno de tutela jurisdicional, consagrando-o como direito fundamental, e, outorgando-lhe uma proteção jurídica diferenciada no âmbito da ordem jurídico-constitucional pátria. (BAHIA; ABUJAMRA, 2007, p. 07)

Segundo Ingo Wolfgang Sarlet:

O direito à saúde pode ser considerado como constituindo simultaneamente direito de defesa, no sentido de impedir ingerências indevidas por parte do Estado e terceiros na saúde do titular, bem como - e esta a dimensão mais problemática impondo ao Estado a realização de políticas públicas que busquem a efetivação deste direito para a população, tornando, para além disso, o particular credor de prestações materiais que dizem com a saúde, tais como atendimento médico e hospitalar, fornecimento de medicamentos, realização de exames da mais variada natureza, enfim, toda e qualquer prestação indispensável para a realização concreta deste direito à saúde. (SARLET, 2007, p. 17)

\footnotetext{
${ }^{3}$ Terminologia dada por SARLET (2001).
} 
A Constituição Federal de 1988, seguindo o exemplo da Organização Mundial de Saúde, reservou um lugar de destaque para a saúde, tratando-a, de modo inédito no constitucionalismo pátrio, como um verdadeiro direito fundamental. E, nas palavras de Luís Roberto Barroso:

[...] Qualificar um dado direito como fundamental não significa apenas atribuir-lhe uma importância meramente retórica, destituída de qualquer consequiência jurídica. Pelo contrário, conforme se já se apresentou aqui, a constitucionalização do direito à saúde acarretou um aumento de sua força normativa, com inúmeras consequências práticas daí advindas, sobretudo no que se refere à sua efetividade, aqui considerada como a materialização da norma no mundo dos fatos, a realização do direito, o desempenho concreto de sua função social, a aproximação, tão íntima quanto possível, entre o dever-ser normativo e o ser da realidade social. (BARROSO, 1996, p. 83)

Para cumprimento desse dever que a Constituição lhe impõe, o Estado instituiu entidades públicas, ora pertencentes à Administração direta, ora à Administração indireta, bem como criou mecanismos de cooperação entre essas entidades e entre entidades do setor privado, de modo que a execução das políticas públicas de saúde se efetive de modo universal e igualitário, observando as peculiaridades regionais e sociais da população que atende.

Contudo, não obstante ao dever do Estado de concretizar politicas públicas capazes de garantir a efetividade do direito à saúde, tem-se paralelamente, uma demanda extremamente elevada que compromete as condições atuais do Estado em manter ativos certos projetos, uma vez que, o poder judiciário assume o papel de intervenção, judicializando, assim, o direito à saúde.

\section{O FENÔMENO DA JUDICIALIZAÇÃO DO DIREITO À SAÚDE}

O Estado Democrático de Direito tem como base a concretização dos direitos fundamentais, principalmente no que tange o princípio da dignidade da pessoa humana. É nesse contexto que os poderes públicos estão vinculados à função de promover a efetivação dos direitos sociais, dentre os quais está inserido o direito à saúde. Para a concretização dos direitos fundamentais incumbe ao Poder Público incrementar a intervenção no domínio econômico e social, um dos mecanismos utilizados para efetivar os direitos é a criação de políticas públicas.

Revista Brasileira de Direitos e Garantias Fundamentais | e-ISSN: 2526-0111 | Porto Alegre | v. 4 | n. 2 |

p. $99-113$ | Jul/Dez. 2018 
Ocorre, no entanto, que analisando a realidade brasileira, e o crescimento exponencialmente do número de decisões judiciais que obrigam, coercitivamente, a administração pública a fornecer os mais diversos medicamentos e prestações de saúde, verifica-se a ineficiência na prestação do serviço básico de saúde bem como a individualização nos casos concedidos pelo judiciário.

Nesse contexto, ocorre o fenômeno político-social denominado judicialização do direito à saúde, isto é, o Poder Judiciário assume o papel determinante para efetivação do direito fundamental da saúde.

Nas palavras trazidas por Luís Roberto Barroso:

[...] judicialização significa que algumas questões de larga repercussão política ou social estão sendo decididas por órgãos do Poder Judiciário, e não pelas instâncias políticas tradicionais: o Congresso Nacional e o Poder Executivo (...). Como intuitivo, a judicialização envolve uma transferência de poder para juízes e tribunais, com alterações significativas na linguagem, na argumentação e no modo de participação da sociedade[.... $]^{4}$ (BARROSO, s.d; s.p)

Isso importa dizer que, estritamente no que refere-se à saúde, judicialização ${ }^{5}$ é o confronto do direito individual com o coletivo e com a política pública estabelecida em matéria de saúde.

Com isso, tem-se visto, no exercício do direito à saúde, positivado em nosso ordenamento jurídico com a Constituição Federal de 1988, contornos nunca vistos, compelindo magistrados, promotores de justiça, procuradores públicos, advogados, entre outros operadores do direito, a lidarem com temas oriundos do Direito Sanitário e da política pública de saúde, nos três níveis de governo.

\footnotetext{
${ }^{4}$ Esse fenômeno tem causas múltiplas. Algumas delas expressam uma tendência mundial; outras estão diretamente relacionadas ao modelo institucional brasileiro.

5 Judicialização é um processo relativamente recente, datado dos fins do século XIX. Como consequência da Revolução Francesa, iniciou-se a implementação da jurisdição única (ou inafastabilidade da jurisdição) e ampliação dos poderes dos juízes, considerando que o Procedimento Civil moderno (...), seguindo sua concepção original, (...) primou pelo desaparecimento dos privilégios de classe e de casta. (CARVALHO, 2010, p. 16). As ideias de liberdade e igualdade paulatinamente aproximaram a sociedade do Judiciário o único que poderia resolver um agravo ou proporcionar um direito ora não concretizado. Movimento parecido trouxe a judicialização à evidência no Brasil, após a redemocratização trazida pela Constituição de 1988. O legislador preconizou a dignidade humana, o acesso sem empecilhos à Justiça, a inafastabilidade da jurisdição e revigorou a importância do Judiciário, que se tornou o grande guardião das garantias e direitos humanos fundamentais e, literalmente, a última guarida para busca dessas prerrogativas.
} 
O direito de se valer do Poder Judiciário para executar essa obrigação é tão certo quanto o dever do Estado à prestação de atendimento médico e assistência farmacêutica, tanto que a própria Constituição Federal o assegura (artigo $5^{\circ}$, inciso XXXV).

No entanto, quando a Administração é constrangida, por vias jurisdicionais, a prestar, indiscriminadamente, atendimento médico e assistência farmacêutica, os cofres públicos sofrem impacto financeira, tendo em vista a ausência de programação desta despesa no orçamento, comprometendo o funcionamento do Estado como um todo e não apenas da estrutura do Sistema único de saúde (SUS).

\begin{abstract}
Não há dúvidas que a judicialização decorre do aumento da democracia e da inclusão social, representados pela positivação dos direitos socais e pela difusão da informação e da consciência cidadã. No entanto, também é fruto das debilidades do Legislativo, ao manter a indefinição do arcabouço legal, e do Executivo, por atuar na ausência de definição de normas ou parâmetros que impeçam as instituições estatais, por serem tão precárias, de se responsabilizar pela peregrinação dos usuários em busca da atenção à saúde. (FLEURY, 2012, p. 15)
\end{abstract}

Por mais bem intencionado que esteja o poder judiciário no intuito de conferir aplicabilidade a determinadas normas legais, não pode tentar suprir todas as carências sociais relacionadas à saúde, mediante a expedição de uma ordem judicial, face à inexistência de condições materiais capazes de viabilizar sua eficaz implementação.

O Judiciário ao determinar uma dada prestação social, sem observar qualquer tipo de limites, poderá gerar efeito oposto, inviabilizando atendimento de outras necessidades coletivas, para as quais já havia um prévio planejamento, mas que ficará comprometido com o desvio.

Ao Judiciário não cabe ditar o destino de aplicação, tampouco, como devem ser direcionadas as forças patrimoniais dos orçamentos públicos, que não tenham uma destinação legal e previamente definida. Contudo, enquanto o direito à saúde estiver sendo negligenciado pelo poder público, caberá ao Judiciário a indeclinável tarefa de lastreado na parcela de soberania que lhe cabe no conceito da tripartição dos poderes, assegurar, pela via coativa, que o Executivo desincumba-se das prestações a ele constitucionalmente atribuídas, dentre as quais se destacam as prestações na área do direito a saúde, em benefício da população a que deve servir.

Revista Brasileira de Direitos e Garantias Fundamentais | e-ISSN: 2526-0111 | Porto Alegre | v. 4 | n. 2 |

p. $99-113$ | Jul/Dez. 2018 
Diante desse contexto, importante trazer à análise os impactos que essas medidas trazem e ainda trarão ao poder público, considerando o aumento contumaz de demandas que clamam pela prestação do Estado num âmbito individual, a fim de ver efetivo seu direito fundamental à saúde.

\section{IMPACTO DA JUDICIALIZAÇÃO DA SAÚDE NA GESTÃO PUBLICA}

A gestão pública é uma estrutura orgânica do Poder Executivo que constitui os âmbitos da União, Estados e Municípios relacionando-se, no exercício das suas funções, com os Poderes Legislativo e Judiciário.

Por sua vez, o Poder Judiciário, foi criado como um poder neutro politicamente, devido ao fato de o princípio da legalidade existir para aplicar o direito, fazendo com que as leis elaboradas sejam feitas essencialmente pelo Poder Legislativo, assim, concedido ao judiciário, o atributo de não solucionar apenas litígios entre as partes, mas de anular atos do Estado.

No entanto, na prática, muitas vezes, ocorre a interferência por parte dos tribunais em políticas públicas, com o consequente desvio de recursos públicos, para particulares que buscam a efetivação dos seus direitos constitucionais de maneira individual, impactando dessa forma, as finanças públicas.

É fato que o sistema de saúde no país não tem sido capaz de efetivar a contento o Direito à Saúde de todas as pessoas, conforme previsto na Constituição Federal. Demasiadamente, o Judiciário acaba sendo a última alternativa de muitos pacientes para obtenção de um medicamento ou tratamento de alto custo, não disponibilizado pelo sistema único de saúde (SUS).

De acordo com pesquisa realizada recentemente pelo Ministério da Saúde a despesa total com remédios frutos de brigas judiciais chegou a $\mathrm{R} \$ 1,2$ bilhões em 2016 , quase $7 \%$ do orçamento previsto pela pasta para compras de medicamentos e insumos para toda a rede em $2016^{6}$, sendo que esse percentual subiu em $20 \%$ no ano de 2017 . Esses dados soam como um

\footnotetext{
${ }^{6}$ Fonte:https://noticias.uol.com.br/saude/ultimas-noticias/redacao/2017/04/06/gasto-com-10-remediosmais-pedidos-na-justica-para-o-sus-chega-a-r-1-bi.htm), acesso em 28 jan. 2018.
} 
alerta, considerando que, em um futuro breve, poderá haver escassez de recursos, até mesmo, para o cumprimento judicial dessas medidas.

O que se verifica é que uma ordem judicial demasiadamente onerosa, fora dos limites orçamentários do Estado, poderá inviabilizar o funcionamento de todo o aparelho administrativo.

Nas palavras de Rodriguez (2004), a atuação dos magistrados deve ser com foco em assegurar a cidadania e a concretização dos direitos fundamentais, mas há questões que acabam contrariando esta atuação do Poder Judiciário. Com isso, a probabilidade de se criar problemas na repartição e gerência de recursos se traduz em um impacto negativo da judicialização da saúde na gestão pública, sendo que, as consequências desses atos serão suportadas pela população de um modo geral.

A gestão pública atua na estruturação e na organização dos bens de um Estado, com poder político e autoridade para gerir atividades e negócios de uma repartição ou empresa pública, para que estes funcionem conforme o que se espera.

\footnotetext{
Na gestão pública há uma diversidade de tarefas que são estabelecidas conforme determinação das leis, dando competência àqueles que são parte integrante da máquina pública de um Estado. Assim sendo, estes são obrigados a prestarem contas por meio de relatórios públicos para serem avaliados pelo parlamento e sociedade em geral. (LOPES, 2010, p. 36)
}

Reforça Di Pietro (2007) que, a gestão pública é importante considerando o fato de que esta é uma máquina do povo, do bem público que, além de administrar e organizar, também é coisa pública que permite a organização de algo público, definitivamente. Nesse ponto, as lições trazidas por Bliacheriene e Santos (2010), retratam que os impactos na concessão dessas medidas judiciais acabam por prejudicar diretamente os setores do orçamento público e financeiro das políticas públicas.

O impacto no orçamento público está ligado ao critério econômico, com a redistribuição de recursos endereçados aos projetos e às políticas públicas, direcionados ao atendimento de particulares, por meio de demandas de interesse individual.

É notório o dever do Estado em arcar com o Direito fundamental à saúde, mas, da forma como o judiciário vem tratando o tema, faz com que a redistribuição dos recursos destinados ao interesse coletivo seja mitigada em face do interesse desse particular. 
Ao decidir pela concessão de uma medida, o judiciário deve se pautar na máxima do princípio da razoabilidade e da proporcionalidade, considerando que não se pode sacrificar interesse coletivo em prol do interesse particular. O dever do Estado é assegurar um direito de forma coletiva, criando mecanismos para que nessa esfera o particular tenha seu direito efetivado.

\title{
Conforme Luiz Werneck Vianna:
}

\begin{abstract}
[...] levando em consideração o crescimento dos gastos com as decisões judiciais e das despesas com remédios do Sistema Único de Saúde, verifica-se uma tendência do Estado ter maiores gastos com o fornecimento de medicamentos em decorrência destas decisões judiciais de casos individuais, comparado com o fornecimento de remédios distribuídos para a coletividade. Tal fato demonstra a forte influência que a judicialização possui sobre a saúde com evidente impacto sobre o orçamento público. (VIANNA, 1999, p. 42)
\end{abstract}

As deficiências, materializadas na ineficácia do Estado em manter uma prestação jurisdicional que garanta a efetividade do direito à saúde faz com que o judiciário se obrigue a intervir, com vistas a garantir tal direito. Contudo, há de se ater para que não prevaleça uma onda exacerbada de demandas que comprometam a atuação do Estado em prol da coletividade.

Para Bliacheriene e Santos (2010), o impacto financeiro negativo da judicialização na saúde ocorre nos casos em que o poder judiciário toma decisões as quais, podem interferir diretamente nas atividades já planejadas por parte do poder público e que precisam ser efetivadas por meio de políticas públicas. Esse sacrifício do interesse coletivo em prol do interesse individual é que tende a acarretar demasiado ônus para o Estado e, consequentemente, para a população.

A Constituição de 1988 prevê em seu artigo 196 que a saúde é um direito de todos e dever do Estado e, como aqui exposto, o Estado atua como forma de efetivar este direito por meio do SUS, de modo integral e universal. Todavia, Vianna (1999) explica que o SUS ainda não conseguiu efetivar de forma concreta o princípio do atendimento integral conforme estabelecido na Constituição Federal, tendo em vista a limitação dos recursos que possui. Nesse caso, os usuários acabam por recorrer ao judiciário para asseirar o acesso a medicamentos e procedimentos de alto custo.

Neste contexto, Luís Roberto Barroso salienta que: 
São comuns programas de atendimentos integral, no âmbito dos quais, além de medicamentos, os pacientes recebem atendimento médico, social e psicológico. Quando há alguma decisão judicial determinando a entrega imediata de medicamentos, frequentemente o Governo retira o fármaco do programa, desatendendo a um paciente que o recebia regularmente, para entregá-lo ao litigante individual que obteve a decisão favorável. Tais decisões privariam a Administração da capacidade de se planejar, comprometendo a eficiência administrativa no atendimento ao cidadão. Cada uma das decisões pode atender às necessidades imediatas do jurisdicionado, mas, globalmente, impediria a otimização das possibilidades estatais no que toca à promoção da saúde pública (BARROSO, 2007, p. 154).

Os impactos causados pela judicialização da saúde na gestão pública geram instabilidade orçamentária, causa deformidades entre a distribuição dos recursos - e o planejamento de novas políticas, além, das distorções provocadas diretamente na administração desses novos projetos.

Nesse viés, considerando a importância de se alavancar políticas públicas eficientes, capazes de suprir as demandas do sistema único de saúde e, paralelamente, o desvio desses recursos de forma individual, pode-se dizer que a judicialização da saúde se mostra negativa e distante de atingir a coletividade.

O direito de recorrer ao judiciário é consagrado constitucionalmente, todavia, a judicialização da saúde possui um caráter que individualiza os direitos, mitigando o coletivo em detrimento do direito individual. E, a resposta para esse impasse, sobretudo, para a ineficácia do Estado na prestação jurisdicional não se respondeu neste estudo, uma vez que, os impactos identificados no orçamento destinado às políticas coletivas hão de prevalecer, já que a judicialização da saúde tende a crescer face à ausência de atuação do Estado.

Portanto, visualiza-se na verdade a necessidade de uma constitucionalização do acesso à saúde percebendo o direito como prerrogativa do Estado Democrático brasileiro devendo ser efetivado por políticas públicas constitucionais que permitam efetiva garantia do direito à saúde sem o expresso controle do judiciário.

A concretização do direito à saúde é um processo sem fim, que passa pelo comprometimento de inúmeras instâncias de poder. Na verdade, o melhor seria que os Poderes Públicos buscassem a concretização dos direitos fundamentais, cumprindo a Constituição, oferecendo um serviço de saúde de qualidade a toda a população, independentemente de qualquer manifestação do Poder Judiciário. Como atualmente essa 
situação ideal se faz distante da realidade, a atuação jurisdicional se faz e, ainda se fará, muito presente.

\section{CONCLUSÃO}

Em face de tudo aqui exposto, apreende-se que a judicialização da saúde merece atenção de todos os setores da sociedade, pois seu crescimento desenfreado poderá trazer graves consequências para o equilíbrio orçamentário do país. A saúde é um direito humano fundamental, mas encontra-se mal implementado e esse é o principal fator que desencadeia a expansão do movimento jurisdicional. No entanto, é necessário haver um equilíbrio entre a consecução do direito individual e das políticas públicas previstas, para que o orçamento público não seja onerado em demasiado, a ponto de se tornar inviável a atuação do Estado.

A crescente judicialização da saúde provoca um efeito desorganizador no orçamento destinado à saúde nos três entes federados, tornando-se um grande desafio financiar e implementar os serviços de saúde universal e gratuito nos Estados. Necessário saber reconhecer que, como um direito fundamental, o direito a saúde não é absoluto e, por isso, é passível de restrições quanto à sua aplicação pelo Poder Judiciário.

O judiciário não pode adentrar nas politicas públicas, ora estabelecidas pelo Executivo, permitindo que o direito individual se sobreponha aos direitos de toda a coletividade, indo além da própria Constituição Federal. Os impactos causados pela judicialização da saúde na gestão pública refletem diretamente no orçamento público-financeiro, pois o que se verifica é um amplo e contínuo aumento de demandas judiciais visando à satisfação de um interesse individual.

O cenário atual na saúde pública, com suas deficiências, tende a aumentar a sua judicialização. É necessário diálogo entre os setores da saúde pública, as Defensorias Públicas, Procuradorias do Estado e o Poder Judiciário para o desenvolvimento de boas práticas que possam amenizar o quadro caótico retratado quase que diariamente.

Espera-se, contudo, o dia em que não será mais necessária à intervenção judicial na concretização do direito à saúde pelo simples fato de ser este um direito do cidadão e um dever do Estado assegurado pela Constituição e concretizado através de políticas públicas constitucionais. 


\section{REFERÊNCIAS}

BAHIA, Cláudio José Amaral; ABUJAMRA, Ana Carolina Peduti. Segunda Seção. A justiciabilidade do direito fundamental à saúde: concretização do princípio constitucional da dignidade da pessoa humana. Revista dos Tribunais. São Paulo, v. 892, n. 99, fev/2010.

BARROSO, Luis Roberto. Da falta de efetividade à judicialização excessiva: direito à saúde, fornecimento gratuito de medicamentos e parâmetros para a atuação judicial. Revista RPGR, Porto Alegre, v.31, n.66, p.89-114, jul/dez, 2007.

BARROSO, Luís Roberto. O Direito Constitucional e a Efetividade de Suas Normas: limites e possibilidades da Constituição Brasileira. $3^{\text {a }}$ ed. São Paulo: Renovar, 1996.

BARROSO, Luís Roberto. Judicialização, ativismo judicial e legitimidade democrática. [s.d.], [s.l]. Disponível

em http://www.direitofranca.br/direitonovo/FKCEimagens/file/ ArtigoBarroso_para _Selecao.pdf, acesso em 02 fev. 2018.

BLIACHERIENE, Ana Carla; SANTOS, José Sebastião dos. Direito à vida e à saúde: impactos orçamentário e judicial. São Paulo: Atlas, 2010.

BRASIL. Constituição (1988). Constituição da República Federativa do Brasil, de 05 de outubro de 1988. Disponível em:

www.planalto.gov.br/ccivil_03/constituicao/constituicaocompilado.htm, acesso em: 21 dez 2017.

BRASIL. Lei 8.142 de 28 de dezembro de 1990. Dispõe sobre a participação da comunidade na gestão do Sistema Único de Saúde (SUS) e sobre as transferências intergovernamentais de recursos financeiros na área da saúde e dá outras providências. Diário Oficial da União, Brasília, DF, 31 dez.1990. Disponível em: . www.planalto.gov.br/ccivil_03/leis/18142.htm, acesso em: 15 dez. 2017

BRASIL. Lei 8.080 de 19 de setembro de 1990. Dispõe sobre as condições para a promoção, proteção e recuperação da saúde, a organização e o funcionamento dos serviços correspondentes e dá outras providências. Diário Oficial da União, Brasília, DF, 20 set. 1990. Disponível em: < http://www.planalto.gov.br/ccivil_03/leis/18080.htm>., acesso em: 15 dez. 2017.

CARVALHO, Ernani Rodrigues de. Em busca da judicialização da política no Brasil: Apontamentos para uma nova abordagem. Revista Sociologia Política, Curitiba, 23, p. 115-126, nov. 2004. 
CARVALHO, Carlos Eduardo Araújo de. Judicialização e legitimidade democrática. Jus Navigandi, Teresina, ano 15, n. 2620, 3 set. 2010. Disponível em http://jus.com.br /revista/texto/17325, acesso em 12 jan. 2018.

FLEURY. Sônia. Judicialização pode salvar o SUS. Saúde em Debate, Rio de Janeiro, v.36, n. 93, p.159, abr./jun. 2012. p. 15, acesso em 27 jan. 2018.

Organização Mundial da Saúde. Constituição da Organização Mundial da Saúde. Organização das Nações Unidas, 1946.

LOPES, Mauricio Caldas. Judicialização da saúde. Rio de Janeiro: Lumen Juris, 2010.

PIOVESAN, Flávia. Direitos Humanos e o Direito Constitucional Internacional. 3. ed. São Paulo: Max Limonad, 1997.

RODRIGUEZ, Eduardo Andres Ferreira. Débitos judiciais no orçamento público: Algumas considerações. Revista de Informação Legislativa, Brasília, v. 41, n. 163, p. 391 a 402, jul./set. 2004.

SANTOS, José Sebastião dos. Direito à vida e à saúde: impactos orçamentário e judicial. São Paulo: Atlas, 2010.

SARLET, Ingo Wolfgang. A Eficácia dos Direitos Fundamentais. Porto Alegre: Livraria do Advogado, 2001.

SARLET, Ingo Wolfgang. Algumas considerações em torno do conteúdo, eficácia e efetividade do direito à saúde na Constituição de 1988. Diálogo Jurídico, Salvador, CAJ Centro de Atualização Jurídica, n. 10, 11 set. 2007. Disponível em: http://www.direito publico.com.br, acesso em 14 nov. 2010.

SARLET, Ingo Wolfgang; TIMM, Luciano Benetti. Direitos Fundamentais, orçamento e "Reserva do Possível. 2. ed. rev e ampl. Porto Alegre: Livraria do Advogado, 2010.

SEVERO, Álvaro Vinícius Paranhos; JÚNIOR, Faustino Rosa. Os direitos da pessoa humana na Constituição Federal de 1988: os direitos sociais podem ser pleiteados na via judicial? In: ASSIS, Araken de (Org.). Aspectos polêmicos e atuais dos limites da jurisdição e do direito à saúde. Porto Alegre: Nota dez, 2007.

SILVA, José Afonso da. Curso de Direito Constitucional Positivo. São Paulo: Malheiros, 1997.

VIANNA, Luiz Werneck. A Judicialização da Política e das relações sociais no Brasil. Rio de Janeiro: Revan, 1999. 